\title{
The Changing Images of China in Straits Times in the 1970s
}

\author{
Huang Lingyi \\ College of Foreign Languages and Cultures \\ Xiamen University \\ Xiamen, China \\ ilovexmu2015@126.com
}

Keywords: Straits Times; English Press; National Image; Singapore Media;China-Singapore Relation

Abstract. The current booming academic researches on media and national image analys is in China fail to pay attention to Singapore English press due to constraints of language and research orientation, which does not match Singapore's influence and position considering the long-term bilateral relationship and the fast-improving exchanges between the two countries. Starting from German philosopher Hans-Georg Gadmer's Philosophical Hermeneutics, the author would argue that being restrained by the prejudice, the influence of power and tradition, the general public, even researchers often fail to understand the whole scope of a certain phase of history. By using the content analysis and data statistics of news reports in Strait Times, coupled with relevant survey results, unfolding the general truth while focusing on key incide nts, the author would try to reveal a more truthful picture of the bilateral relationship between China and Singapore in the 1970s. Relevant news reports in Singapore Chinese newspapers would be provided on key incidents as a contrast. As is shown from the perspective of Singaporeans, which differs from previous historical analysis from Chinese standpoints, it would give a more complete and significant landscape of history and further deepen the understanding the power of prejudice in history.

\section{Introduction}

The current burgeoning academic research on media and national image analysis in China has generated great interest inside scholarly circles as well as official institutions. Notable progress can be seen in research on countries ranging from English-speaking countries like America, Britain to neighboring ones like Japan and Russia. Yet, due to constraints of language and research orientation, scholars in China have failed to pay sufficient attention to Singapore's English print media and devote most attention to Singapore Chinese ne wspapers. However, currently the largest newspaper in Singapore is the Straits Times, which has a circulation of 365,800 and a readership of 1.43 million and a record 191 million page viewers on ST online websites in 2012[1]. Insufficient research into the leading newspaper is a significant oversight.

Moreover, as the only country in Southeast Asia where the Chinese form an overwhelming part of the population (76\%), Singapore is a special case to study. It would be interesting to analyze the media in a country that is perceived as a "friendly neighbor", to find out whether our perception is correct or not, in contrast to those on countries that are usually deemed as "hostile" or "with mixed feeling" (see ; Jiang,2010[2]; Liu,2007[3]; Sun, 2010 [4], Sun2009[5]). Does the shared ethnicity bring ethnic affinity? Or it is a wishful thinking from the China's part?

To find out whether this perception meets the reality, the paper chooses to analyze the national images from the perspective of media. A qualitative cum descriptive content analysis will be applied to reports in Straits Times in the 1970s, with an aim of addressing the following questions:

What are the elements that influence Singapore English press? Do they exert influence on the reports on China? What's the role of Singapore English press in Singapore? Whose voice does it stand for? Would it be able to reflect or affect the public opinion? Did the common ethnicity affect media neutrality when it comes to report on China? Did it act as a positive or negative factor? Did China's national image change in the 1970s? If yes, to what degree and any turning points? If yes, 
what were the possible reasons behind these changes? If no, why the images remained constant? Could researchers expect further changes in the time beyond this time phase? If yes, what's the possible outcome?

Although the paper uses media as a research target, yet as a study in historical international relations, it aims to investigate the important elements that influence media on their reports of the national image, and its response in bilateral relationship. It would not fall into the typical mass communication pattern that entirely depend on technical analysis results. Socio-historical context will be provided and political theories will be applied to certain results. In a period that is still obscure to most Chinese youth, it offers an alternative interpretation of that phrase of history, which is shown from the perspective of Singaporean and differs from previous historical analysis from Chinese standpoint, providing us with the possible chance of correcting our past perceptions.

\section{Data Collection}

The data in this research will mainly focus on the largest English newspaper in Singapore---Straits Times. And time period set for analysis is January 1st, 1970 to December 31st, 1979, covering the whole 1970s. The items searched are on the website of National Library of Singapore http://newspapers.nl.sg/Default.aspx, which offers digital version of main newspapers in Singapore. As the website offers a choice of search based on keywords, the author use "China Singapore Relations" as the keyword to search the whole database on Straits Times, set the time phase to 1970s (1970-1979), and limit the type to "article, then the author get 815 results.

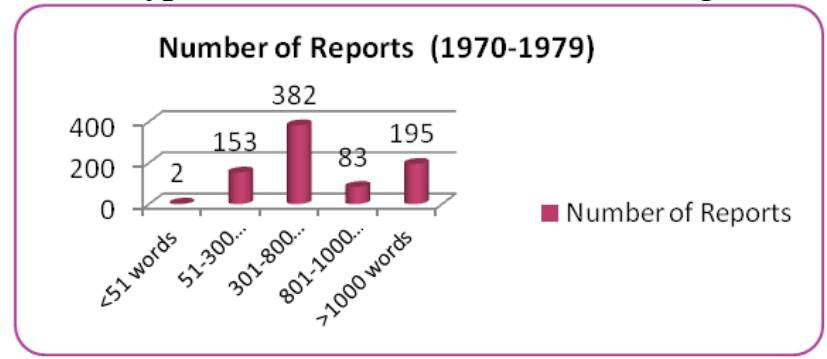

Fig. 1 Number of News Reports on "China Singapore Relation" in Straits Times (1970-1979) by Word Counts table 1 Number of News Reports on “China Singapore Relation” in StRaits Times (1970-1979) by Years

\begin{tabular}{|l|c|c|c|c|c|c|c|}
\hline Year & No. & Year & No. & Year & No. & Year & No. \\
\hline $\mathbf{1 9 7 0}$ & 23 & $\mathbf{1 9 7 2}$ & 89 & $\mathbf{1 9 7 4}$ & 55 & $\mathbf{1 9 7 6}$ & 68 \\
\hline $\mathbf{1 9 7 1}$ & 92 & $\mathbf{1 9 7 3}$ & 94 & $\mathbf{1 9 7 5}$ & 84 & $\mathbf{1 9 7 7}$ & 66 \\
\hline $\mathbf{1 9 7 8}$ & 125 & $\mathbf{1 9 7 9}$ & 119 & & & & \\
\hline
\end{tabular}

As a preliminary attempt, the author restricts the search result to reports with word counts $>1000$ to make initial analysis. According to the theory of agenda-setting, the more salient a news issue is in terms of frequency and prominence of coverage - the more important audiences will regard the issue to be. For a newspaper, articles that are more than 1000 words cover a considerable large part of a page, and because of the eye-catching layout, the normal reader will seldom miss the report, even they just read the title. This is the way the media use to shape the perception of the audience. Or in in Bernard Cohen's words, "tell us [(the public)] what to think about."[6]And the wording (1000 plus) also allows enough space to further analyze or fully portray the whole picture of certain reports or speeches.

I must point out that the author do not mean that news reports that have less than 1000 words are not important or do not report facts. Reports that have words above 300 all well deserve studying and will provide a more complete source of research. And they surely will be an important part of my 
further research. But for preliminary attempt, the author just starts from the longest ones to evaluate the possible effectiveness of the method and give hints to further wider scope of analysis.

Hence, when the restriction comes to word counts $>1000$, the number of reports goes to 195 , and the number of articles each year is as follows:

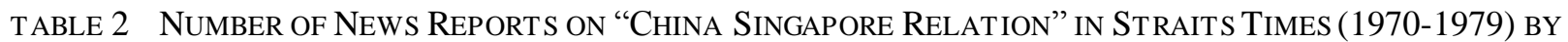
YEARS WITH WORD COUNTS $>1000$

\begin{tabular}{|c|c|c|c|c|c|c|c|}
\hline Year & No. & Year & No. & Year & No. & Year & No. \\
\hline 1970 & 3 & 1972 & 23 & 1974 & 11 & 1976 & 20 \\
\hline 1971 & 18 & 1973 & 17 & 1975 & 14 & 1977 & 66 \\
\hline 1978 & 29 & 1979 & 33 & & & & \\
\hline
\end{tabular}

Compared Table the author with Table II, the trend is similar-upward increasing, with no big fluctuation and with lowest point in 1970 --the first year of the decade, and highest in 1978 or 1979 - the end of the decade. The sharpest contrasts appear in year 1972, 1976, and 1977, 1979, where longer passage account for much larger portion of the whole $(25.8 \%, 29.41 \%, 40.9 \%$ and $27.73 \%$ respectively). The reasons will be analyzed in the following parts. However, generally speaking, when the number of two sets of reports reveal similar trend, the restriction of the sample length does not significantly affect the research outcome.

\section{Findings of the News Reports}

Among the 198 news items under the keyword "China and Singapore Relations", only 88 items match the topic "Sino-Singaporean Relationship". The author labels each item following the time sequence. The first item is 9 November 1970 and the last one is 20 November, 1979.

The Speakers in the News Reports. The first finding comes to the "speakers in the news". Among the 88 items, 47 items are news reports about Prime Minister's or Minister's (including other countries' officials) speeches or interviews, which makes up 53.4\% of the total. And Singaporean politicians' speeches account for $80.85 \%$ of these speech reports, showing a fact that as a Singapore newspaper, it concentrates more on its own leaders' speeches. The Prime Minister Lee Kuan Yew is the most cited source of these reports, whose speeches or interviews total at 24 items or $27.27 \%$, a much higher percentage than other politicians. The second one is the Foreign Minister S. Rajaratnam, 7 speeches are included. Other politicians include Acting Foreign Minister and Minister of Defense Dr Gh Keng Swee, Minister of Culture Yeun, Acting Foreign Minister E.W. Baker, etc.

Content The mes. The contents of the newspaper articles are classified into three main themes: Diplomacy, Economy and Culture. Among all reports, articles on Diplomacy still stand first at $61.36 \%$, and economy content follows at $20.45 \%$ while culture content at $12.50 \%$. The percentage coincide with those of reports on Lee Kuan Yew. It indicates that among all the factors, diplomacy is the most important element in the Sino-Singaporean relationship at that period. In an era when international system has not been fully stabilized and conflicts between the communism and capitalism still dominant the ideology, it was understandable for such a high percentage. Moreover, in the first half of the decade, China was busy with its Cultural Revolution which started at 1965 and put little focus on its economics. Only when Deng came to power in 1976 and set up the reform policy and Four Modernization Plan did China begin to shift its focus to economics. The visit of Lee Kuan Yew to China and Deng's visit to Singapore further pushed forward the bilateral economic cooperation, therefore after 1976 the percentage of news on economy increased and report focus change from mostly diplomacy to mixing diplomacy with economy. 
The Changing Images and Changing Relations. As the author mentions previously, ideology, leadership, economic development, varied regional and international relations, even media censorship and laws are relevant factors that influence the news reports on China and Singapore relations, thus the new reports in Straits Times portray a series of changing images of China.

1970-1971: Suspicious, yet slowly ice-thawing stage. After the founding of republic in 1965, the most important thing for People's Action Party (PAP) was to ensure the survival of this tiny citystate, with its complicated multiracial migrant background. With $76 \%$ ethnic Chinese, yet surrounded by a Malay world, and a hostile Sukarno regime in Indonesia, Singapore had to work skillfully to react to the feeling of its neighboring counties. And at the same time, China's policy toward Singapore was not friendly. China's reaction to Singapore's independence was "first ambivalent and later, at worst unfriendly and hostile"[7]. China even took sides with Communist Party of Malaya (CPM) and the Barisan Socialis who claimed the independence was "fraud" and that of PKI (Communist Party of Indonesia) who claimed Singapore's independence was a "neo-colonial scheme, manipulated by British Imperialism"[8].

Therefore, in 1970, news items related to China were the lowest in number for the whole decade, with only 2 out of the 88 items, and the timing was also interesting, Nov 9th and Dec 31st (This one was a review of the whole year and did not only focus on China). This trend can be echoed if researchers extend the time limit to 1965, after applying the same search limits, the results are quite similar:1965 (3 items), 1966 (9 items), 1967 (13 items), 1968 (3 items) and 1969 (7 items); and these do not rule out those that are irrelevant. The limited coverage even gives us a feeling of refrain. And the image of China remains mainly as a country that is hostile to Singapore government, supporting the communists in Southeast Asia, interfering into Southeast Asian countries' affairs and finding a way back into the world powers.

The only item concerning China in 1970 is entitled "Wither the Nixon Doctrine?"[9], which describes the major Southeast Asian countries' reactions to China's attempts for coming back into the UN, saying,

[Singapore and Indonesia] are making their own offers of the olive branch to China. But Singapore Foreign Minister Rajaratnam has raised anew the suspicion that is common in the region: the problem is whether one of the big powers - the United States - will be in the game, or will turn her back and pull out of Asia.

In contrast to the previous hostile attitude, Singapore supported China's back into UN. The pulling-out of America can be seen as an important factor in changing Singapore's attitude towards China. However, Singapore changed policy not out of the ethnic similarity, but act as a result of active reaction to changing power relations in the world.

Year 1971 has seen more reports ( 7 items) and the tone of the news report began to sound more positive, the newspaper cited the Foreign Minister's words for supporting China' s reentry into UN,

The participation of the People's Republic of China in the work of our organization will at last make it truly representative of nearly all of humanity. [‥]It was cold war considerations which had kept Communist China out of this organization. [ $\cdots$ ]The status of Taiwan is a domestic matter to be settled by the people of China including those of Taiwan. [10]

Considering Singapore's long-term friendly relationship with Taiwan, this indicates the government tried to make people understand the new international situation where the US tried to have contact with China and the world power relations changed, Singapore should readjust its position. Then China was no longer that kind of county that should be singled out and isolated. Instead, Singapore should contact and support its return to UN.

Most interestingly, on November 23rd, 1971, the newspaper carried an item "Friends from all over are welcome, but not tourists", describing a journalist's trip to China and his experience and talks with a Chinese official from the Council for the Promotion of International Trade, who introduced proudly the situation of the Chinese People's daily life. This item was followed by a 
series "China-through the eyes of S'porean"[11] which journalists reported directly from Peking, describing the different treatment to overseas Chinese and foreigners (as Singaporean Chinese were now listed as "foreigners"). In contrast to hard life, the ideological loyalty still dominates most Chinese thought at that time.

Although China's economy was weak at that time, in Lee's eyes, China will become the 'thirdpole" [12] of the world and push the world trade to further development. At the end of 1972, China's image had turned to be more positive in terms of economic prospect.

1972-1975 Adjusting stage. Actually in this stage Singapore's foreign relations towards China remained basically the same, in Lee Kuan Yew's words, "We are happy to continue trade with China through existing non-diplomatic channels and let our neighbors initiate change".[13]

The major concern became how to deal with the problem of "communism", for China still supported the activities of Communist Party of Malaya and Communist Party of Indonesia, which was seen by Singapore as a threat to stability of the Southeast Asia. Nevertheless in 1971, Lee expressed his understanding of China's stand by saying,

I believe Mr Chou En-Lai [] is pursuing policies in China's national interests. There is a distinction between national interests and ideological interests. Where the two conflicts, and then national interest are placed first. However, ideological fraternal parties will continue to be helped. [14]

Through continued exchanges of information, situation move towards a favorable side for Singapore, which made Lee Kuan Yew believe "in the next decade, particularly with a new generation in charge, China's support for guerrilla insurgency may become moral than material"'.[15]China was frank in its own concerns[16] and learned about what Southeast Asian countries' worries. Both sides began to adjust for better relations.

Second focus is the emphasis on building up of the national identity of Singaporeans. Lee wanted to create a new generation of Singaporean, conscious not only of China but of the whole world. In his words, "we are a center of communication-and our people must be alive to the influence of all big powers in the world."[17] Even the Foreign Minister S Raja. made it quite clearly that "[s]omething like 75 per cent of the population was of Chinese origin. Some liked to believe they are Chinese, but researchers believe they are Singaporean." And to avoid being regarded as a third China, "we don't mind the last in the queue [to have diplomatic relationship with China].'[18] To Singaporeans, China now can only be the past origin; clear line must be drawn and establishing formal foreign relationship had to be pushed backward.

Further adjustment can be seen in the Foreign Minister's visit to China in May 1975, which is "the first visit by a Singapore minister to China" and a series of news reports elaborating on the diplomatic and economic topics exchanged by leaders of the two countries further clarified certa in things. "Hitherto, researchers have known about what your leaders think and how they perceive their role in Asia and the world only second and third hand"[19], Raja explained. "Some 15 delegations of professional and business organizations had visited China since 1971 and there would be few more such visits this year." [20]In other words, Singapore and China would expect further exchanges in the future. This revealed an implicit message that due to the lack of face-to-face talks, the past reports may have possibility of distortion, and the conception of China may involve some misleading or incorrect factors. They used this to justify the change of attitude and make pavement for future cooperation.

And during the talk, China made it clear that "Singaporeans were like the Americans, Australians and New Zealanders, ethnically of one stock, but politically separate peoples from those of their forefathers' home country."'[21]The message revealed a positive adjustment from the Chinese side-- understanding the Singaporean government's concern about national identity, Chinese government also expressed their willingness to adjust and cooperate. Here researchers see a more 
peaceful and friendlier image of China, which understand the counterpart's baseline and try to collaborate under basic guidelines.

1976-1979 Further Improving stage. The final stage in the 1970s had seen two important visits, which made the bilateral relation move forward. In May 1976 Lee Kuan Yew paid the first visit to Beijing, which can be interpreted as "a de facto normalization short of de jure diplomatic recognition between the two states"[22]. And this was further confirmed by Deng Xiaoping's visit to Singapore in 1978.

The relationship between two countries did make further progress, especially in the field of economic cooperation. In September 1977, the first Chinese ceramics exhibition of contemporary products from China had been organized and Mr Rajaratnam described Singapore as "a more profitable outlet for Chinese porcelain and Earthenware than China"[23]. And this can be seen as an example to reveal the cooperative potential of the future bilateral trade, in which China was seen as a good trade partner with great potentials.

And this change of focus can be seen more clearly after 1978 when China began its four modernization programs. China was regarded as one of the "five major world powers"[24].The bilateral trade further blooms. Detailed descriptions of the trade volume and activities demonstrated to us a fast-developing bilateral trade with great benefits for both sides and China became the important partner in terms of economic interests. The positive image of an economic partner even a "competitor"[25] was reinforced by the successive news reports and detailed figures.

Despite the positive image from bilateral trade, another unsettled issue was still about "communism". If China continued its two-tiered relationship (state-to-state and party-to party relations simultaneously, it was hard for Singapore and other Southeast As ian countries to relieve their worries. This can be seen from a repetitive mentioning of Communist activities and China's attitude towards communists in Southeast Asia in Foreign Minster's or Lee's speech. [26] Yet these can be tolerated when there are great economic benefits ahead. It can be argued that the reason why Singapore opposed China's party-to-party policy was "aimed more at seeking solidarity with the ASEAN states rather than as a serious bone of contention between China and Singapore"[27]. Therefore it was easy to understand why Singapore would accept Deng Xiaopeng's assurance in 1978 that China did not "seek to interfere with the domestic affairs of Malaysia or Singapore. $[\cdots]$ How the Singapore government dealt with the communists in Singapore was none of China's business."'[28]And China's support of the communist movements in the ASEAN states was based on ideological and moral reasons. And China believed "such support should not be considered as interference into Singapore' $s$ internal affairs'[29].

Since the 1960s, the issue of communist movements in Malay had always been a major concern to Singapore government and China was always connected with the image of being a supporter with an aim of subverting the Singapore government. Yet now, the news reports emphasized and clarified China's stance and position and explained why they would continue to take the dual track policy, giving a chance for China to explain some of its concerns and constraints and cleared out the concerns for possible interference. Although leaders in Singapore continued to express their suspicions, with a clear shift of focus to economic cooperation, China's image did get clarified and improved.

\section{Conclusions}

Press in Singapore has never functioned as the Fourth Estate in the Western Liberalist tradition. It is better described as guided and government-controlled. It functions under two premises: it can be abused to destroy social harmony and political stability or it can play a constructive role in nationalbuilding, the latter of which is often interpreted as a "pro-government stance"[30].

This is reflected clearly in the large proportion (53.4\%) of leaders' speeches and interviews in the total reports. When portraying a country that is ethnically important, the newspaper devotes most of 
its coverage to leaders' public speeches, while marginalizing common people's attitude or observance, which can be seen as a biased attitude for support for government policy. It may be argued that in the 1970s, China locked itself to the outside world, and had no formal diplomatic relationship with Singapore, which made it politically irrelevant. Yet inadequate news coverage from the perspective of ordinary people, even journalists is still an oversight.

Admittedly, in the 1970s, an era that was characterized by struggles for press freedom against tightening-up the control, researchers cannot expect too much difference between the report of leading English newspaper and the attitude of the government. After all, for a newspaper that is to shoulder the responsibility of national-building, it has to be sensitive about its reports on a country that should be treated with extra carefulness.

Furthermore, from the analysis of the news content, researchers can infer that political and socioeconomic factors play an important role in influencing the attitude or perspective of the news. The legal framework and censorship practice predetermine the scope of the contents and topics that may provoke racial issues are carefully tackled or even deliberately avoided. In a newly-founded state, with complicated multiracial background, news reports concerning China were reported without an inclination and avoid showing Chinese chauvinism. Actually in the beginning of the decade, reports on China were limited and kind of hostile and suspicious. The large percentage of ethnic Chinese in Singapore did not act as a positive factor in the news reports. On the contrary, it functions as a constraint or even a negative feature.

The influence of leaders is the most obvious and to some extent dominant factor among these influential indicators. From the proportion of speakers cited, the Prime Minster and minsters are the main source of the speeches and interviews, making up $43.18 \%$ of the total. And these reports set the tone of the government on the treatment of the is sues related to China, conveying to people what's the official attitude and what would expect from the people. Language shapes the thoughts and identities of people and determines their social behavior and political attitude. If a concept or image is reinforced through constant emphasis or referring, it would gradually be imposed on the audience, which is deemed as the "power" to influence.

This is typical in the "communism threat" issue, which the leaders, scholars persistently, in varied occasions, stress the seriousness of the issues, keep reminding the audience about the possible subversion threat of communist guerrillas (the news reports that involve communism make up $17.32 \%$ of the total report). China was constantly related to the support, first materially and ideologically and later only ideologically. Therefore, China's image cannot be disconnected with the issue of "communism" in the 1970s, and at the beginning stage, was portrayed as a hostile country that tried to extend its revolution outside, even with an aim of subverting Singapore regime. Even after the two countries began their formal contact in 1975, and China adjusted its attitude towards communists' activities in ASEAN countries and promised not to interfere into Singapore governments' actions against communists at home, the topic still accounted for a large portion of the whole reports, yet gradually gave way to economic reports that emphasized more on the positive development of the bilateral relationship. And China's image began to be increasingly connected with a trade partner which can bring great economic benefits for Singapore and even pose competition in the future.

In the 1970s, in Singaporean's eyes, China's image did go through a series of changes. For most ethnic Chinese Singaporeans, it was the homeland of their forefathers, yet they no longer recognized dual citizenship in 1978, and urged them to adopt loyalty to the land they live. It is a communist regime, which in early stages tried to extend its communism out to Southeast Asia, yet with improving diplomatic relationship with ASEAN countries and under the war pressure from the Soviet Union, chose to adopt friendlier relations with the Capitalist countries and support the onceimitate communists' activities in Southeast Asian countries only ideologically. It chose to lock itself and "say no even to tourists", believing in its ability to rely on oneself. Its people lived hard life, yet never considered fleeing the country or questioned the Mao's ideology. It finally opened the door to 
the outside world in 1978 when Deng came to power, and presented great economic potentials in bilateral trade for Singapore and even would become a competitor in years to come. From a communist country that aggressively tried to spread its ideology and revolution to a fast-developing economy that seek technological and economic advice from Singapore, China became more pragmatic, more peaceful and more adjustable to the changing situation.

The turning point of the image change appeared after the visit of the Foreign Minster S. Raja. to China, which was the first for ministers. The two countries had face-to-face negotiation and clarified certain things, for the information they had before were second and third hand. After that visit, followed by Lee Kuan Yew's visit and Deng's visit, the reports sounded more positive and gave more emphasis on the economic parts, while diplomacy still remained a focus. The main reason for a greater percentage of longer reports in 1972, 1976, 1977 and 1979 is that either in or directly after these years, some important event happened in the diplomatic field, namely the visit of Nixon to China, the visit of Lee Kuan Yew to China, the Visit of Deng Xiaopeng to Singapore. Thus, the impact of politics on media contents can be seen clearly.

In the whole decade, China's image didn't go through dramatic changes; on the contrary, the changes tended to be more gradual and subtle. Diplomacy remained the focus of reports all through the decade with economic reports coming up after Deng' s visit in 1978. And the issue of Communism still remained unsolved at the end of decade, although it did show signs of compromise. And reports on cultural exchanges were few and not analyzed deeply within these reports. (It is interesting to contrast with Renmin Ri Pao, in which most of the reports concerning Singapore were about cultural exchanges.)

In the 1980s and 1990s, the international and internal situation underwent further changes. SinoSingapore relationship would expect more new dimensions. It can be predicted that economic reports would multiply in those decades when economic cooperation become the main focus. And what other factors and impacts can be seen in the media still remain to be seen. Internally, changing socioeconomic variables, like education standards, affluence and literacy meant that the press has to keep in step with the dynamic news environment in which they are operating in.[30] With the English literacy increases and Straits Times becomes the No. 1 newspaper in Singapore, as well as the challenges posed by internet and new media, those impact on the public opinions become the new research orientation, and further studies would be done in the future.

In a word, ideologies conveyed in newspaper or other media "take on the significant meaning and convey specific power relations" only when being accepted by the majority of the community and reaching a social consensus.[31] Although it is hard to determine by exact statistics whether the Singapore government and the Straits Times successfully portrayed an image of China they wanted or to what extent people accepted the image their illustrated, one thing is certain that the Singapore Identity has been successfully built up and Singaporeans regard themselves as Singaporeans, totally different from their forefathers. China is and will only be a country where some of their ancestors ever lived.

\section{References}

[1] “ST online Websites draw record 191m page views” , The Straits Times, June 52012 ,p B5.

[2] Jiang, Z.Q., The Image of China in America. Beijing: Remin Publishing House,2010.

[3] Liu, L.L., The Image of China in Japan's Mass Media, Beijing: China Media Publishing House, 2007.

[4] Sun, F., The Image of China in Russia. Beijing: Remin Publishing House,2010.

[5] Sun, Y.Z., Decoding China' s Image - Contrast of the Reports on China in New York Times and Times, Beijing: World Knowledge Publishing House,2009. 
[6] Cohen, B.,The Press and Foreign Policy. New York: Harcourt,1963.

[7] Shee Poon Kim, "Singapore's Foreign Policies towards the People's Republic of China since 1965", in Carino, T.C. (etd) China ASEAN Relations: Political, Economic \& Ethnic Dimensions. Manila: China Studies Program, De La Salle University, page 101,1991.

[8] Straits Times, 8th, November 1965.

[9] "Wither the Nixon Doctrine?", Straits Times,9 November,1970,p10.

[10] "Strategy for survival", Straits Times, 12 October, 1971, p 10.

[11] "China-through the eyes of a S'porean", Straits Times, 20th December, 1972, p 14.

[12] "How five nations can help ensure stability", Straits Times, 2 December, 1972, p 16.

[13] Straits Times, 29th March, 1973.

[14] 'Lee: S'pore can be beat the pull-out", Straits Times, 6 September, 1971, p17.

[15] "S-EA view of the new power balance in the making", Straits Times, 2 April, 1973.

[16] "Peking is so frank in its own way". Straits Times, 2 April, 1975, p 2.

[17]Asian Research Bulletin, May 1-31, 1971 and New York Times, 20th May 1971.

[18] "Why US has to stay on: Raja", Straits Times,27 April, p1.

[19] "The Singapore Identity", Straits Times, 15th Mach, 1975, p1.

[20] Ibid.

[21] Ibid.

[22] Shee Poon Kim, 'Singapore's Foreign Policies towards the People' s Republic of China since 1965” , in Carino, T.C. (etd) (1991), China ASEAN Relations: Political, Economic\& Ethnic Dimensions. Manila: China Studies Program, De La Salle University, p107.

[23] "Urged to start incentive schemes for their workers". Straits Times, 4th September 1977, p 4.

[24] "The vital questions of the 80s, Straits Times",20th April 1979,p1.

[25] “China will pose formidable competition in the next few years, Govt to set the LED”, Straits Times, 30 June, 1979, p1.

[26] Straits Times 5 June, 1978; 12June, 1978; 7 October 1978; 17 October, 1978.

[27] Shee Poon Kim, "Singapore's Foreign Policies towards the People's Republic of China since 1965” , in Carino, T.C. (etd) (1991), China ASEAN Relations: Political, Economic\& Ethnic Dimensions. Manila: China Studies Program, De La Salle University, p 107.

[28] "Teng to 'sell' the idea that Peking is really friendly towards ASEAN". Straits Times ,12 November, 1978.

[29] Shee Poon Kim, 'Singapore's Foreign Policies towards the People' s Republic of China since 1965” , in Carino, T.C. (etd) (1991), China ASEAN Relations: Political, Economic\& Ethnic Dimensions. Manila: China Studies Program, De La Salle University, page 107.

[30]Nadarajan, B., The Ideological Orientation of the Straits Times, thesis of National University of Singapore, 1995.

[31] Ibid. 